\title{
Fracture resistances of roots prepared with rotary files with different metal alloys and motion kinetics
}

\author{
Emel Uzunoğlu, ${ }^{1}$ Eda Ezgi Aslantaş, ${ }^{1}$ Sevinç Aktemur Türker \\ ${ }^{1}$ Department of Endodontics, Hacettepe University Faculty of Dentistry, Ankara, Turkey \\ ${ }^{2}$ Department of Endodontics, Bülent Ecevit University Faculty of Dentistry, Zonguldak, Turkey
}

\begin{abstract}
Objective: To compare the forces required to vertically fracture roots prepared with files made of different metal alloys and applied with different motions during preparation.

Methods: A total of 60 decoronized mandibular incisors that were balanced with respect to buccolingual-mesiodistal diameters were selected. Fifteen unprepared roots were selected as controls. The remaining 45 specimens were assigned randomly into the following experimental groups: preparation with the ProTaper Universal (Group 1), preparation with the ProTaper Next (Group 2) and preparation with the Reciproc (Group 3). The prepared and unprepared samples were loaded vertically at a crosshead speed of $1 \mathrm{~mm} / \mathrm{min}$ until vertical root fracture occurred. The results were statistically evaluated with 1-way analysis of variance and Tukey's post-hoc tests.
\end{abstract}

Results: Statistically significant differences between groups were detected $(P<.05)$. The statistically highest mean fracture resistance was obtained in the control group. There were no significant differences between the forces required to fracture the prepared samples ( $p>05)$. The majority of samples were fractured catastrophically in a labiolingual direction.

Conclusion: The prepared samples were more prone to vertical root fracture compared with the unprepared samples. Neither motion kinematics nor the alloys of the files significantly influenced the fracture resistances of the prepared roots.

Keywords: Fracture resistance; M-wire; ProTaper Next; Reciproc; vertical root fracture.

$\mathrm{T}$ he principle aim of root canal shaping is to chemomechanically clean the entire root canal system without damaging the integrity of the tooth. However, numerous complications during root canal preparation have been reported and include ledge formation, transportation, perforation $^{[1]}$ and dentinal micro-cracks, which could potentially result in vertical root fractures (VRFs). ${ }^{[2,3]}$ VRFs are a serious clinical problem that can lead to the extraction of teeth. ${ }^{[4,5]}$ Wilcox et al. ${ }^{[6]}$ concluded that preserving the dentin is important for preventing VRFs.
The majority of clinicians prefer to use nickel-titanium (Ni-Ti) rotary file systems because they have advantages such as shortening the treatment period and greater cutting efficiency. ${ }^{[7,8]}$ However, the increased stress on the root canal walls that occurs during preparations with these files could result in the development of cracks. Kim et al. ${ }^{[9]}$ reported that there is potentially a relationship between the design of the Ni-Ti instruments and the incidence of vertical root fractures.

Correspondence: Dr. Emel Uzunoğlu. Hacettepe Üniversitesi Diş Hekimliği Fakültesi,

Endodonti Anabilim Dalı, Ankara, Turkey.

Tel: +90 312 - 3052260 e-mail: emel_dt@hotmail.com

Submitted: February 01, 2016 Accepted: March 09, 2016 
ProTaper Universal rotary files (PTU; Dentsply Maillefer, Ballaigues, Switzerland) are widely used in many countries. Their design facilitates active cutting motion and removes relatively more dentin coronally compared with other systems. ${ }^{[10]}$ ProTaper Universal rotary files are made from a conventional superelastic $\mathrm{Ni}-\mathrm{Ti}$ wire. Over the last decades, technological advancements in rotary $\mathrm{Ni}$ - $\mathrm{Ti}$ instruments have led to new design concepts and easier, faster and better root canal shaping. M-wire is a special $\mathrm{Ni}-\mathrm{Ti}$ alloy that provides increased flexibility and improved resistance of the instruments to cyclic fatigue. ${ }^{[11,12]}$ Recently, the ProTaper Next (PTN; Dentsply Maillefer, Ballaigues, Switzerland) and Reciproc (R; VDW, Munich, Germany) instruments were introduced; these instruments are made from M-Wire technology but differ in characteristics such as the cross-section geometry and the motion kinetics that are applied during preparation. The PTN has an off-centered rectangular design and progressive and regressive percentage tapers on a single file. Ruddle $^{[13]}$ reported that the off-centered rectangular design decreases the screw effect, dangerous taper lock and the torque on any given file by minimizing the contact between the file and the dentin. The Reciproc is able to prepare canals with only a single instrument and has an identical S-shaped cross-sectional design with sharp cutting edges. The results regarding the potential for dentinal damage according to the metal alloys of rotary files and the motion kinetics applied during root canal preparation are controversial. ${ }^{[14-18]}$

Several studies have compared the incidence of dentinal microcracks after root canal instrumentation with these files; ${ }^{[14-19]}$ however, the fracture strengths of roots prepared with these systems have not yet been compared; therefore, the goal of this ex vivo study was to compare the force required to vertically fracture roots prepared with the abovementioned $\mathrm{Ni}$-Ti rotary files, which are made of different alloys, constituted of different tapers and different number of files and moved differently during preparation. The null hypothesis was that there would be no differences regarding effects on vertical root fracture resistance values between these file systems.

\section{Materials and methods}

Extracted human mandibular incisors with straight roots were selected for this study. Teeth with open apices or anatomic irregularities were excluded. All selected teeth were decoronated perpendicular to the long axis of the tooth using a diamond-coated bur with water-cooling to leave roots of approximately $14 \mathrm{~mm}$ in length to ensure straightline access and provide a reference plane. All roots were observed in a stereomicroscope under x12 magnification
(Olympus Corporation, Taichung, Taiwan) to exclude any external defects or cracks, and the teeth were discarded if any of these characteristics were found. Mesiodistal and buccolingual radiographs were acquired to verify the presence of a single canal. With the aim of specimen standardization, the mesiodistal and buccolingual diameters of the coronal planes were measured with a digital caliper, and the mean mesiodistal $(3.7 \mathrm{~mm})$ and buccolingual $(5.6 \mathrm{~mm})$ dimensions were obtained. Thereafter, the roots that exhibited a difference of $20 \%$ from the mean were discarded. ${ }^{[20]}$ Teeth of approximately the same widths were selected for this study as much as possible. Sixty roots with comparable canal widths were finally selected and stored in distilled water throughout the study. ${ }^{[21]}$

\section{Tooth preparation}

Fifteen teeth were left unprepared and served as the control group. The remaining 45 teeth were randomly divided into 3 experimental groups of 15 teeth each. Canal patency was established with a size $10 \mathrm{~K}$-file (Dentsply, Maillefer). All teeth in which canal patency could not be established were excluded from the study and replaced with similar teeth. Thereafter, the root canal preparations were performed according to the relevant group (1-3) as described later.

\section{Root canal preparation}

Group 1 (PTU; Dentsply Maillefer, Ballaigues, Switzerland): Fifteen teeth were prepared with the ProTaper Universal (PTU) rotary system. The canals were prepared in a crown-down fashion with the aid of an X-SMART electric motor with torque control (Dentsply, Maillefer). The ProTaper Shaping SX, S1 and S2 and finishing F1 and F2 files were sequentially used with a continuous in-andout movement. The instrumentation sequence was SX at two-thirds of the WL, S1 and S2 at WL $-1 \mathrm{~mm}$ and F1 $(20 / .07)$ and F2 $(25 / .08)$ at the WL. Once the instrument had negotiated the full WL and rotated freely, it was removed. Each file was used with a brushing motion. The torque and other parameters for each file were set as per the manufacturer's recommendations.

Group 2 (PTN; Dentsply Maillefer, Ballaigues, Switzerland): The root canals were prepared using the ProTaper Next (PTN) system with a gentle in-and-out motion at $300 \mathrm{rpm}$ and $2 \mathrm{Ncm}$ torque with the aid of a torquecontrolled endodontic motor (X-Smart). The instrumentation sequences were SX, XI (17/.04) and X2 (25/.06). The SX file was used as in Group 1 , and the X1 and X2 files were used at the full WL.

Group 3 (R; VDW, Munich, Germany): In the Re- 
ciproc ( $\mathrm{R}$ ) group, the canals were first prepared manually with stainless K-files (Dentsply Maillefer) to \#15. An R file $\# 25 / .08$ (VDW) was then used in a reciprocating motion up to the WL using the "reciproc all" mode with the aid of a torque-limited electric motor (VDW Silver Reciproc motor, VDW). The flutes of the instrument were cleaned after 3 pecking motions.

In all experimental and control groups, each canal was irrigated with a freshly prepared $1 \%$ solution of sodium hypochlorite $(\mathrm{NaOCl})$ between the application of each instrument during the preparation procedure using a syringe and a $27-\mathrm{G}$ needle. Approximately $12 \mathrm{~mL}$ of the $\mathrm{NaOCl}$ solution was used for each root canal, and $3 \mathrm{~mL}$ of $17 \%$ ethylene diamine tetraacetic acid was used to remove the smear layer. After the completion of the procedures, the canals were rinsed with $2 \mathrm{~mL}$ of distilled water. All of the roots were covered with moist gauze during the instrumentation. A single experienced operator performed all of the procedures. In each of these 3 test groups, 1 set of instruments was used for the preparation of 5 root canals. After the completion of the preparations, the samples were subjected to a fracture resistance test without any further filling procedures.

\section{Fracture resistance}

The 15 unprepared control and prepared 45 experimental samples were mounted in acrylic resin (Imicryl Ltd., Konya, Turkey) to expose $8 \mathrm{~mm}$ of the coronal part as previously described. ${ }^{[3,21,22]}$ The specimens were secured in the lower plate of a universal testing machine (Model LRX-Plus; Lloyd Instruments, Fareham, UK). A steel spherical tip with a diameter of $3.6 \mathrm{~mm}$ was attached to the upper plate and lowered to contact the circumference of the orifice of each specimen. A vertical loading force was applied at a crosshead speed of $1 \mathrm{~mm} / \mathrm{min}$ until fracture occurred. The force was recorded in Newtons using computer software (Nexygen-MT, Lloyd Instruments). All samples from this study were examined for the pattern of fractures under stereomicroscopic analysis (Olympus Corporation, Taichung, Taiwan $\mathrm{x} 10$ ). Location of failure was recorded as favorable and catastrophic. Root fractures at the cervical third were classified as favorable (reparable) while fractures at the middle and apical thirds were classified as catastrophic (irreparable).

\section{Statistical analysis}

The 1-way analysis of variance (ANOVA) test was used to compare the mean force values recorded for the groups, and Tukey's post hoc tests were used for the pair-wise comparisons between the groups when the analysis of vari-
Table 1. Experimental groups and fracture resistance (FR) values (N) $($ mean $\pm S D)$ of tested samples

\begin{tabular}{ll} 
Experimental groups & FR values (n) \\
Control group & \\
$\quad$ Unprepared teeth & $265.85 \pm 21.23^{\mathrm{a}}$ \\
Group 1 & \\
$\quad$ Teeth prepared with ProTaper Universal & $233.40 \pm 32.78^{\mathrm{b}}$ \\
Group 2 & \\
$\quad$ Teeth prepared with ProTaper Next & $226.33 \pm 31.10^{\mathrm{b}}$ \\
Group 3 & \\
$\quad$ Teeth prepared with Reciproc & $239.09 \pm 37.75^{\mathrm{b}}$ \\
\hline
\end{tabular}

$\mathrm{n}=15$ for each group. Different superscript letters $(a, b)$ indicate significant differences between the groups $(p<.05)$.

ance test was significant. The significance level was set at $\mathrm{p}<.05$. The statistical analyses were performed with IBM SPSS Statistics Version 20 (SPSS Inc, Chicago, IL, USA) for Windows.

\section{Results}

The fracture resistance values $(\mathrm{N})$ are presented in Table 1 as the means \pm the standard deviations (SDs). Statistically significant differences were detected between the groups by $\mathrm{l}$-way analysis of variance $(\mathrm{p}<.05)$. The forces obtained in the unprepared control group were significantly greater than those of the experimental groups $(\mathrm{p}<.05)$. There were differences between the experimental groups $(\mathrm{p}>.05)$. The majority of samples were fractured catastrophically in a labiolingual direction regardless of the preparations system (Figure 1).

\section{Discussion}

VRF is probably the most undesired and remediless clinical problem, and the prevalence of VRFs in endodontically treated teeth has been increasing in recent years. ${ }^{[4,5]}$ Various procedures that are utilized during endodontic treatments have been found to induce the formation of tiny cracks that can result in VRFs during sustained function.
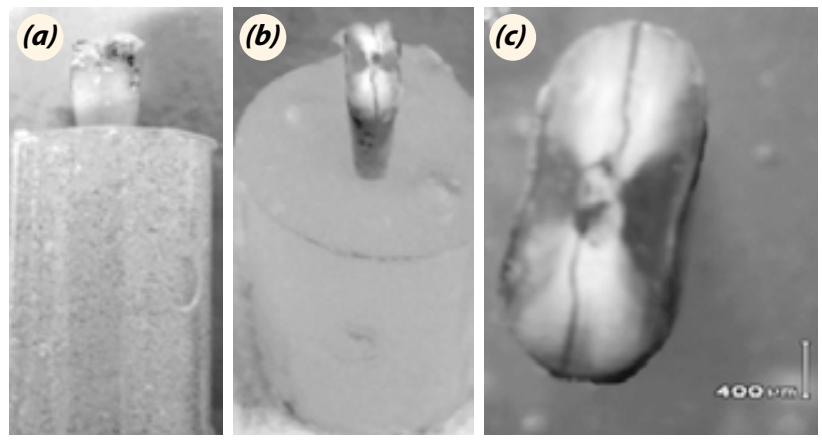

Fig. 1. (a) Sample embedded in acrylic resin. (b) Sample after fracture test. (c) Stereomicroscopic image of fracture pattern. 
${ }^{[23-25]}$ Kim et al. ${ }^{[9]}$ reported that stiffer file designs generate higher stress concentrations, which increase the risk of dentinal defects that may lead to root cracking. This stiffness is related to the cross-section, size, taper, method of manufacturing and the material from which the instrument is manufactured. ${ }^{[12]}$ Time-saving Ni-Ti rotary files are used during root canal treatment by the majority of clinicians. However, studies that have evaluated the potentials for microcrack formation associated with the use of these files have reported that they induce microcracks. ${ }^{[10,14,16,18]}$ In contrast, studies that have evaluated the force required to vertically fracture roots prepared with different rotary files are limited. ${ }^{[2,3,21,26]}$ Therefore, the aim of this $e x$ vivo study was to compare the forces required to vertically fracture unprepared roots and roots prepared with three different rotary file systems that are manufactured from different alloys, with different tapers and applied with different motion kinematics. Furthermore number of files that are used to prepare the root canal in each system is different. The results of present study revealed that dentin removal significantly affected the fracture strength as has been reported in previous studies. ${ }^{[2,22]}$

There are controversial results regarding motion kinematics in the literature. While Liu et al. ${ }^{[15]}$ Ashwinkumar et al. ${ }^{[16]}$ and Kansal et al. ${ }^{[18]}$ reported that reciprocating motion significantly affects the VRF and is more generous and creates less dentinal damage compared with continuous rotation, Bürklein et al. ${ }^{[14]}$ reported that reciprocating files produce significantly more incomplete dentinal cracks. However, there were differences in the experimental designs of these studies; for example, Ashwinkumar et al. ${ }^{[16]}$ and Kansal et al. ${ }^{[18]}$ tested the WaveOne file, while Liu et al. ${ }^{[15]}$ and Bürklein et al. ${ }^{[14]}$ tested Reciproc files with different apical diameters. In the present study, the motion kinematics was not found to affect the forces required to fracture the prepared samples. Although the majority of studies have reported the presence of cracks after preparation, ${ }^{[14-16,18,19]}$ De-Deus et al. ${ }^{[17]}$ recently reported that there is no causal relationship between dentinal microcracks and root canal preparations performed with the Reciproc, WaveOne and BioRaCe systems. Furthermore, Arias et al. ${ }^{[27]}$ used a cadaver model to evaluate microcracks and reported that neither taper nor shaping motion seemed to affect the induction of microcracks at any of the observed levels. Tavanafar et al. ${ }^{[28]}$ reported that instrumentation with the single-file reciprocating technique (WaveOne) was associated with resistance to fracture comparable with the roots prepared with NiTi hand or rotary instruments (BioRaCe). Also Çiçek et al. ${ }^{[29]}$ reported there were no statistically significant difference amongst samples prepared with PTU, PTN and WaveOne regarding resis- tance values that are needed to fracture roots vertically. In contrast, there are no available data in the literature regarding comparisons of the Reciproc and ProTaper Next systems in terms of fracture strength. Thus, the findings of this study can only be compared with studies in which the microcracks associated with these systems were compared.

The Reciproc and ProTaper Next files are also made of $\mathrm{M}$-wire and are more flexible than files made from conventional Ni-Ti wire. ${ }^{[11,12]}$ Abou El Nasr and Abd El $\operatorname{Kader}^{[3]}$ reported that the alloy from which an instrument is manufactured is a more important factor in determining the damaging potential of single-file instruments than the motion of instrumentation. Capar et al. ${ }^{[19]}$ reported fewer microcracks with the PTN (X2;25/.06 apical taper) compared to the PTU (F2; 25/.08 apical taper). These authors suggested that the cross-sectional geometry or the M-wire technology might have been the factors that caused this result. ${ }^{[19]}$ PTU instruments have a triangular cross-sectional geometry, whereas PTN instruments are rectangular. In contrast, the Reciproc (25/.08 apical taper) has an identical S-shaped cross-sectional design with sharp cutting edges. However, in the present study, neither alloy nor cross-section geometry affected the forces required to vertically fracture the prepared roots. In another study, Capar et al. ${ }^{[30]}$ reported that root canal instrumentation with PTN files up to size X2 and PTU files up to size F2 alter the root canal volumes to similar extents, which could be one explanation of the similarity of the forces required to fracture the roots prepared with the PTN and PTU observed in the current study. In the present study taper of files and/or number of files also did not cause any statistically significant differences between the fracture values. This result is consistent with previous studies. ${ }^{[28,29]}$

Previous studies have reported that the application of a force vertically to the long axis of the tooth transmits the force uniformly ${ }^{[31,32]}$ Therefore, in the present study, a single load was applied vertically until fracture to evaluate the fracture resistances of the prepared roots. No root canal filling procedures were performed in these experiments to acquire information about the effects of the files on the forces required for fracture compared with those required in the unprepared control group. Moreover, Lertchirakarn et al. ${ }^{[23]}$ assumed that VRFs are most commonly attributable to the stresses generated within the canal during filling or post placement in the canal.

The limitations of this study were the use of extracted teeth and the absence of a simulation of the periodontal ligament. Extraction time, storing conditions, age of teeth and anatomic variations of the roots may affect the results of a study, ${ }^{[21]}$ It is essential to standardize the samples 
before mechanical tests. According to results of Soros et al. ${ }^{[24]}$ periodontal simulation with acrylic resin and elastomeric impression material was deemed to be reliable. However, embedding samples to acrylic resin without periodontal simulation has been used in previous studies, ${ }^{[3,21,22]}$ and this experimental design also provides comparable data. However, the interpretation of these data should be performed with caution because it is difficult to correlate these results directly with clinical practice.

Within the limitations of this ex vivo study, it can be concluded that root canal preparations significantly affected the forces required to fracture roots; however, neither the motion kinematics nor the alloys of the files elicited significant effects on the fracture strength of the prepared roots. Thus, the null hypothesis of the study was accepted. Further studies are required to evaluate the effects of different file characteristics on VRFs.

\section{Acknowledgement}

Authors deny any conflict of interest.

Conflict of interest: None declared.

\section{References}

1. Mozayeni MA, Asnaashari M, Modaresi SJ. Clinical and Radiographic Evaluation of Procedural Accidents and Errors during Root Canal Therapy. Iran Endod J 2006;1:97100.

2. Singla M, Aggarwal V, Logani A, Shah N. Comparative evaluation of rotary ProTaper, Profile, and conventional stepback technique on reduction in Enterococcus faecalis colony-forming units and vertical root fracture resistance of root canals. Oral Surg Oral Med Oral Pathol Oral Radiol Endod 2010;109:105-10. Crossref

3. Abou El Nasr HM, Abd El Kader KG. Dentinal damage and fracture resistance of oval roots prepared with single-file systems using different kinematics. J Endod 2014;40:849-51. Crossref

4. Shemesh H, van Soest G, Wu MK, Wesselink PR. Diagnosis of vertical root fractures with optical coherence tomography. J Endod 2008;34:739-42. Crossref

5. Touré B, Faye B, Kane AW, Lo CM, Niang B, Boucher Y. Analysis of reasons for extraction of endodontically treated teeth: a prospective study. J Endod 2011;37:1512-5. Crossref

6. Wilcox LR, Roskelley C, Sutton T. The relationship of root canal enlargement to finger-spreader induced vertical root fracture. J Endod 1997;23:533-4. Crossref

7. Schäfer E, Lau R. Comparison of cutting efficiency and instrumentation of curved canals with nickel-titanium and stainless-steel instruments. J Endod 1999;25:427-30. Crossref

8. Vaudt J, Bitter K, Neumann K, Kielbassa AM. Ex vivo study on root canal instrumentation of two rotary nickeltitanium systems in comparison to stainless steel hand instruments. Int Endod J 2009;42:22-33. Crossref

9. Kim HC, Lee MH, Yum J, Versluis A, Lee CJ, Kim BM. Potential relationship between design of nickel-titanium rotary instruments and vertical root fracture. J Endod 2010;36:1195-9. Crossref

10. Bier CA, Shemesh H, Tanomaru-Filho M, Wesselink PR, $\mathrm{Wu} \mathrm{MK}$. The ability of different nickel-titanium rotary instruments to induce dentinal damage during canal preparation. J Endod 2009;35:236-8. Crossref

11. Alapati SB, Brantley WA, Iijima M, Clark WA, Kovarik L, Buie C, et al. Metallurgical characterization of a new nickel-titanium wire for rotary endodontic instruments. J Endod 2009;35:1589-93. Crossref

12. Gutmann JL, Gao Y. Alteration in the inherent metallic and surface properties of nickel-titanium root canal instruments to enhance performance, durability and safety: a focused review. Int Endod J 2012;45:113-28. Crossref

13. Ruddle CJ. The ProTaper endodontic system: geometries, features, and guidelines for use. Dent Today 2001;20:607.

14. Bürklein S, Tsotsis P, Schäfer E. Incidence of dentinal defects after root canal preparation: reciprocating versus rotary instrumentation. J Endod 2013;39:501-4. Crossref

15. Liu R, Hou BX, Wesselink PR, Wu MK, Shemesh H. The incidence of root microcracks caused by 3 different single-file systems versus the ProTaper system. J Endod 2013;39:1054-6. Crossref

16. Ashwinkumar V, Krithikadatta J, Surendran S, Velmurugan N. Effect of reciprocating file motion on microcrack formation in root canals: an SEM study. Int Endod J 2014;47(7):622-7. Crossref

17. De-Deus G, Silva EJ, Marins J, Souza E, Neves Ade A, Gonçalves Belladonna F, et al. Lack of causal relationship between dentinal microcracks and root canal preparation with reciprocation systems. J Endod 2014;40:1447-50.

18. Kansal R, Rajput A, Talwar S, Roongta R, Verma M. Assessment of dentinal damage during canal preparation using reciprocating and rotary files. J Endod 2014;40:14436. Crossref

19. Capar ID, Arslan H, Akcay M, Uysal B. Effects of ProTaper Universal, ProTaper Next, and HyFlex instruments on crack formation in dentin. J Endod 2014;40:1482-4. Crossref

20. Goldberg F, Kaplan A, Roitman M, Manfré S, Picca M. Reinforcing effect of a resin glass ionomer in the restoration of immature roots in vitro. Dent Traumatol 2002;18:702. Crossref

21. Capar ID, Altunsoy M, Arslan H, Ertas H, Aydinbelge HA. Fracture strength of roots instrumented with selfadjusting file and the ProTaper rotary systems. J Endod 2014;40:551-4. Crossref

22. Ashraf H, Momeni G, Moradi Majd N, Homayouni H. 
Fracture Resistance of Root Canals Obturated with Gutta-Percha versus Resilon with Two Different Techniques. Iran Endod J 2013;8:136-9.

23. Lertchirakarn V, Palamara JE, Messer HH. Load and strain during lateral condensation and vertical root fracture. J Endod 1999;25:99-104. Crossref

24. Soros C, Zinelis S, Lambrianidis T, Palaghias G. Spreader load required for vertical root fracture during lateral compaction ex vivo: evaluation of periodontal simulation and fracture load information. Oral Surg Oral Med Oral Pathol Oral Radiol Endod 2008;106:64-70. Crossref

25. Shemesh H, Bier CA, Wu MK, Tanomaru-Filho M, Wesselink PR. The effects of canal preparation and filling on the incidence of dentinal defects. Int Endod J 2009;42:208-13.

26. Lam PP, Palamara JE, Messer HH. Fracture strength of tooth roots following canal preparation by hand and rotary instrumentation. J Endod 2005;31:529-32. Crossref

27. Arias A, Lee YH, Peters CI, Gluskin AH, Peters OA. Comparison of 2 canal preparation techniques in the induction of microcracks: a pilot study with cadaver man- dibles. J Endod 2014;40:982-5. Crossref

28. Tavanafar S, Karimpour A, Karimpour H, Mohammed Saleh A, Hamed Saeed M. Effect of Different Instrumentation Techniques on Vertical Root Fracture Resistance of Endodontically Treated Teeth. J Dent (Shiraz) 2015;16(1 Suppl):50-5.

29. Çiçek E, Aslan MA, Akkoçan O. Comparison of the Resistance of Teeth Instrumented with Different Nickel-Titanium Systems to Vertical Root Fracture: An In Vitro Study. J Endod 2015;41:1682-5. Crossref

30. Capar ID, Ertas H, Ok E, Arslan H, Ertas ET. Comparative study of different novel nickel-titanium rotary systems for root canal preparation in severely curved root canals. J Endod 2014;40:852-6. Crossref

31. Lindemuth JS, Hagge MS, Broome JS. Effect of restoration size on fracture resistance of bonded amalgam restorations. Oper Dent 2000;25:177-81.

32. Dias de Souza GM, Pereira GD, Dias CT, Paulillo LA. Fracture resistance of premolars with bonded class II amalgams. Oper Dent 2002;27:349-53. 